\title{
Obesity and Metabolic Comorbidities: Environmental Diseases?
}

\author{
Carla Lubrano, ${ }^{1}$ Giuseppe Genovesi, ${ }^{1}$ Palma Specchia, ${ }^{1}$ Daniela Costantini, ${ }^{1}$ \\ Stefania Mariani, ${ }^{1}$ Elisa Petrangeli, ${ }^{1,2}$ Andrea Lenzi, ${ }^{1}$ and Lucio Gnessi ${ }^{1}$ \\ ${ }^{1}$ Department of Experimental Medicine, Section of Medical Pathophysiology, Endocrinology and Food Science, "Sapienza" University, \\ Viale Regina Elena, 324, 00161 Rome, Italy \\ ${ }^{2}$ Institute of Molecular Biology and Pathology, National Council of Research (CNR), Piazzale Aldo Moro, 7, 00185 Rome, Italy
}

Correspondence should be addressed to Carla Lubrano; carla.lubrano@uniromal.it

Received 4 December 2012; Revised 22 January 2013; Accepted 5 February 2013

Academic Editor: Chiara De Luca

Copyright (C) 2013 Carla Lubrano et al. This is an open access article distributed under the Creative Commons Attribution License, which permits unrestricted use, distribution, and reproduction in any medium, provided the original work is properly cited.

\begin{abstract}
Obesity and metabolic comorbidities represent increasing health problems. Endocrine disrupting compounds (EDCs) are exogenous agents that change endocrine function and cause adverse health effects. Most EDCs are synthetic chemicals; some are natural food components as phytoestrogens. People are exposed to complex mixtures of chemicals throughout their lives. EDCs impact hormone-dependent metabolic systems and brain function. Laboratory and human studies provide compelling evidence that human chemical contamination can play a role in obesity epidemic. Chemical exposures may increase the risk of obesity by altering the differentiation of adipocytes. EDCs can alter methylation patterns and normal epigenetic programming in cells. Oxidative stress may be induced by many of these chemicals, and accumulating evidence indicates that it plays important roles in the etiology of chronic diseases. The individual sensitivity to chemicals is variable, depending on environment and ability to metabolize hazardous chemicals. A number of genes, especially those representing antioxidant and detoxification pathways, have potential application as biomarkers of risk assessment. The potential health effects of combined exposures make the risk assessment process more complex compared to the assessment of single chemicals. Techniques and methods need to be further developed to fill data gaps and increase the knowledge on harmful exposure combinations.
\end{abstract}

\section{Introduction}

Obesity is an increasing health problem; more than half of the European population is overweight and up to $30 \%$ is obese and its prevalence worldwide doubled since 1980 (World Health Organization 2011) [1]. Similarly, increased body weights have also been reported in pets and laboratory animals over the past decades [2]. Obesity is a condition characterized by significant clinical implications, such as comorbidities and somatic fragility, which seriously affect independence, psychological wellbeing, and overall quality of life $[3,4]$. Obesity is associated with type 2 diabetes mellitus (DM), dyslipidemia, cardiovascular disease, cancer, and obstructive sleep apnea [5, 6]. Medical treatments are often ineffective and bariatric surgery is the only available therapeutic modality associated with clinically significant and relatively sustained weight loss in subjects with morbid obesity [7-9].
Proinflammatory factors are increased in obesity and $\mathrm{DM}$, and the prevalent metabolic state is defined by the term "glucolipotoxicity," in which excess extracellular glucose and fatty acids exert various damaging effects. Obesity and DM-associated oxidative stress eventually lead to systemic inflammation and endothelial cell dysfunction, central to the development of cardiovascular diseases and metabolic syndrome $[10,11]$.

Excess caloric consumption and a sedentary lifestyle are the only recognized risk factors for obesity and DM but alone do not account for the current worldwide obesity epidemic. New hypotheses are emerging to explain the etiopathogenesis of these conditions, including environmental chemicals, stress, immunological alterations, micronutrient deficits, and gut microbiota [12, 13]. Genetic modifications could be involved in predisposition to obesity; however the human genome has not undergone significant modifications over the last years. On the contrary, the correlation between 
accumulation of synthetic chemicals and increase of obesity prevalence might not be a random event. This dramatic change in the environment has led to the hypothesis that some environmental pollutants act as Endocrine Disrupting Chemicals (EDCs), interfering with various aspects of metabolism and of energy balance [14].

\section{Endocrine and Metabolic Disruption}

2.1. EDCs. EDCs have been defined as exogenous substances that alter function(s) of the endocrine system and consequently cause adverse health effects in an intact organism, or its progeny, or (sub)populations. (International Programme for Chemical Safety-IPCS). EDCs can mimic the action of natural hormones or interfere with their production, release, metabolism, and elimination [15]. These substances may derive from natural, animal, human, or plant sources. Phytoestrogens are EDCs found naturally in certain plants, including foods like whole grains, leafy greens, beans, and garlic, and can mimic the action of estrogen, showing some beneficial effect on bone mineral density, insulin resistance, and cardiovascular risk factors in women after menopause [16-20]. Another class of EDCs belongs to the group of heavy metals (i.e., cadmium, mercury, and arsenic). These metals may cause occupational or residential exposure [21]. Heavy metal toxicity can result in reduced mental and central nervous function and damage to blood composition, lungs, kidneys, liver, breast, and other vital organs [22, 23]. Allergies are not uncommon and repeated long-term exposure with some metals may even cause cancer [24, 25]. Major concerns, however, are currently focused on industrial products. In fact, most EDCs are synthetic chemicals designed for use in a variety of industries. Classes of these chemicals are solvents or lubricants and their byproducts (polychlorinated biphenyls (PCBs) and dioxins), plastics, plasticizers (bisphenol A (BPA)), phthalates; pesticides (methoxychlor, chlorpyrifos, DDT) fungicides (vinclozolin), herbicides (atrazine), and antibacterials (triclosan). There are several reports of pollution from PCBs and dioxins that show a direct causal relationship between a chemical and the manifestation of an endocrine, immunological, or metabolic dysfunction in humans and in wildlife [26-29] but the more common event is the widespread persistent exposure to a broad mix of chemicals. Table 1 shows a brief summary of the principal incidents caused by dioxins contamination in the last fifty years.

2.2. Mechanisms of Action. Some EDCs were designed to have long half-lives and therefore are persistent contaminants, do not decay easily, may not be metabolized, or may be broken down into more toxic compounds [30]. Others, such as BPA, although not very persistent in the environment, are so widespread in their use that there is a prevalent human exposure [31]. Humans and wildlife are exposed daily to a variety of compounds, and it is thus likely that even if none reach an effective level, the combination or mixture of chemicals may become dangerous. These chemical mixtures enter the food chain and accumulate in animals up to humans. Exposure occurs also through drinking contaminated water, breathing contaminated air, or contacting contaminated surfaces. They may exert nontraditional dose-response curves, the so-called U-shaped or inverted U-shaped dose-response curve. As a consequence, any level of exposure may cause endocrine or metabolic abnormalities, particularly if the exposure occurs during a critical developmental period, and low doses may even be more potent than high doses $[32,33]$. The age of exposure is important [34], since the environment to which a developing organism (fetal life, childhood) is exposed interacts with the individual's genes to determine the propensity to develop a disease later in life. The majority of environmental factors and toxicants do not alter DNA sequence or promote genetic mutations. Therefore, they may promote abnormal phenotypes or disease through modifications of factors that regulate gene expression such as DNA methylation and histone acetylation [35-39].

EDCs can bind and activate multiple hormone Nuclear Receptors (NRs). Various EDCs share receptors, and thus additive or even synergistic effects may be observed [40]. Among NRs, Estrogen Receptors (ERs) regulate many aspects of metabolism, including glucose transport, glycolysis, mitochondrial activity, and lipid metabolism [41]. It is likely that ER activation modulates neural networks controlling food intake and adipose tissue [42, 43]. Male and female ER knock-out mutant mice show increased insulin resistance and impaired glucose tolerance [44]. Neonatal exposure to a low dose of the estrogenic drug diethylstilbestrol (DES) stimulated a subsequent increase in body weight and an increase in body fat in mice [45]. BPA, a breakdown product of coatings in food and beverage containers, may act as an ER agonist. In the US population, exposure is nearly ubiquitous, and BPA has been detected in fat, blood, and urine [46]. Short exposure to BPA provokes chronic hyperinsulinemia, with perturbations of glucose and insulin tolerance tests [47]. Furthermore, high- or low-dose exposure to BPA during gestation up to puberty leads to hyperlipidemia with increased body and adipose tissue weight in both sexes $[48,49]$. BPA exposure has been shown to disrupt multiple metabolic mechanisms, suggesting that it may contribute to obesity in humans [50-52]. Other studies have demonstrated associations between urinary BPA concentration and adult $\mathrm{DM}$, cardiovascular diseases, obesity, and abnormalities in liver function [53,54] A longitudinal study of apparently healthy adults showed an association between baseline urinary BPA concentration and later-life coronary artery disease [55].

EDCs may also modulate other hormone NRs, particularly thyroid hormone receptor (TR) and glucocorticoid receptor (GR). BPA acts as a TR antagonist in vitro, increases serum thyroxin, and alters RC3/neurogranin expression in the developing rat brain [56]. Brominated Flame Retardants (BFRs) also disrupt the TR pathway, and exposure of rats to Polybrominated Diphenyl Ethers (PBDEs) resulted in a significant increase in lipolysis and a significant decrease in glucose oxidation [57]. Organotins and PCBs can bind GR and alter 11beta-hydroxysteroid dehydrogenase type 2 activity [58].

The body is protected from the accumulation of toxic chemicals by the expression of drug-metabolizing enzymes 
TABLE 1: Examples of dioxin contamination incidents.

\begin{tabular}{|c|c|c|c|}
\hline Year & Country & Type of accident & Cause \\
\hline $1960-1975$ & Vietnam & Contamination by a defoliant, agent orange & Contaminated agent orange \\
\hline 1976 & Italy (Seveso) & $\begin{array}{l}\text { Contamination by a cloud of toxic chemicals of an } \\
\text { area of } 15 \text { square kilometers }\end{array}$ & Accident at a chemical factory \\
\hline 1998 & Germany & Contamination of milk & Contaminated citrus pulp pellet from Brazil \\
\hline 1999 & Belgium & Contamination of poultry and eggs & $\begin{array}{l}\text { Animal feed contaminated with illegally disposed } \\
\text { PCB-based waste industrial oil }\end{array}$ \\
\hline 2004 & The Netherlands & Contamination of milk & Contaminated clay in animal feed \\
\hline 2007 & Europe & Contamination of guar gum (food additive) & $\begin{array}{l}\text { Guar gum from India contaminated by } \\
\text { pentachlorophenol that contains dioxins as } \\
\text { further contamination }\end{array}$ \\
\hline 2008 & Ireland & Contamination of pork meat and products & Contaminated animal feed \\
\hline
\end{tabular}

and transporters. This adaptive response incorporates at least three NRs: pregnane $\mathrm{X}$ receptor (PXR), constitutive androstane receptor (CAR), and aryl hydrocarbon receptor (AhR), as well as xenobiotic metabolic and transporter systems. PXR and CAR are members of the NR super family of sensor receptors and contribute to fatty acid, lipid, and glucose metabolism, and CAR seems to be an anti-obesity NR that ameliorates DM and fatty liver accumulation [5961]. Endogenous ligands of PXR and CAR include some bile acid derivatives, pregnanes, androstane metabolites, and other metabolic products of steroids; exogenous compounds include herbal medicines pharmaceutical drugs and synthetic steroid hormones. A number of EDCs activate both PXR and CAR: nonylphenol, Di (2-Ethylhexyl) Phthalate (DEHP), Mono-(2-Ethylhexyl) Phthalate (MEHP), BPA, some PCBs perfluorooctane sulfonate (PFOS), perfluorooctanoic acid (PFOA), and the organochlorine methoxychlor [62]. AhR is a xenosensor that mediates the biological response to a wide spectrum of xenobiotics; in particular, AhR mediates the toxic effects of dioxins [63]. Endogenous molecules that bind AhR are lipoxin 4, leukotriene derivatives, biliverdin, and bilirubin. Xenobiotics that activate AhR include various dietary phytochemicals, some PCBs, and 2,3,7,8-Tetrachlorodibenzo-p-Dioxin (TCDD). The mechanisms through which AhR regulates energy metabolism are not clearly established; however, crosstalk with ER may be involved. In addition, AhR also indirectly affects adipogenesis through inhibition of Peroxisomal Proliferator-Activated Receptor (PPAR) $\gamma$ expression [64].

2.3. Health Effects. All major endocrine organs are vulnerable to endocrine disruption, including the HypothalamusPituitary-Adrenal axis, reproductive organs, the pancreas, and the thyroid gland $[65,66]$. For example, it has been reported that EDCs, and estrogen mimicking agents among them, prolong the proliferation phase of immature Leydig cells, prior to their maturation [67], and can interfere with peritubular myoid cells [68], and it is known that estrogens are associated with Leydig cell tumorigenesis in mice [6971]. The declining level of androgen during aging, associated with an increasing level of estrogen, has been hypothesized to be important in the development of benign prostatic hyperplasia [72-74], and oral exposure to low-dose BPA seems to aggravate testosterone-induced benign hyperplasia prostate in rats [75]. Several studies have suggested that estrogen exposure may increase the risk of prostate cancer [76], and various hormones such as androgens and gonadotropinreleasing hormone may play a role in prostate cancer cell growth [77, 78]. BPA and dibutyl phthalate (DBP) seem to be able to stimulate the growth of prostate cancer cells [79]. Thyroid carcinoma is the most common endocrine malignancy being about 3 times more common in women than in man [80]. Analogously, in differentiated thyroid cancer (DTC), EDCs with estrogen-like activity may be suspected to play a role in disease progression. Experimental evidence demonstrated that estrogen, but not testosterone, promotes DTC cell proliferation and that this effect could be attenuated by tamoxifen $[81,82]$.

In 2006, Bruce Blumberg developed the "obesogen hypothesis", to explain the weight gain effects of certain chemicals. This hypothesis is supported by laboratory and animal research as well as epidemiological studies that shown that a variety of EDCs can influence adipogenesis and obesity [83-86]. EDCs are also known to impact hormonedependent metabolic systems and brain functionand can be easily found in human blood and urine and epidemiological literature on associations between EDC exposure and body weightis increasing [87-89].

These substances target various endocrine axes and affect adipocyte physiology and more generally the regulation of energy homeostasis [90]. Several persistent organochlorine pesticides and fungicides have been implicated in obesity [91, 92]. Metabolic alterations like metabolic syndrome and type $2 \mathrm{DM}$ are recognizedas obesity comorbid conditions, and EDCs exposure may be involved in their pathogenesis. Such contribution was revealed by comprehensive studies of large and well-characterized cohorts, such as the cohort used for the NHANES (National Health and Nutrition Examination Survey) project $[93,94]$.

Epidemiological studies show an association between dioxins exposure and type 2 DM [95]. High and low 
doses of dioxins affect genes linked with hepatic circadian rhythm, cholesterol biosynthesis, fatty acid synthesis, glucose metabolism, and adipocyte differentiation, in an AhRdependent manner $[96,97]$. Weight control and intermediate metabolism require a precise balance between energy input, storage, and consumption; several NRs are involved. The PPARs act as lipid sensors that act in different organs to adapt gene expression to a given metabolic status [98]. Plasticizers, surfactants, pesticides, and dioxins can modulate PPARs activity, and the phthalates are a group of well-characterized peroxisome proliferators. Mono-(2-Ethylhexyl) Phthalate (MEHP) is proadipogenic in a cell culture model, suggesting that it may act as a metabolic disruptor and may promote obesity in vivo $[99,100]$. Kanayama et al. [101] showed that among 40 EDCs, organotins such as tributyltin (TBT) and bis (triphenyltin) oxide (TPTO) are activators of human PPAR $\gamma$ [102].

\section{Oxidative Stress and Mitochondrial Dysfunction}

An increase in oxidative stress-associated inflammation has been hypothesized to be a major mechanism in the pathogenesis of obesity-related diseases. Additionally, a rise in inflammatory cytokine levels might drive a further increase in oxidative stress, setting up a vicious cycle $[104,105]$. When perturbed, the mitochondrial system alters the output of matter and energy and this may result in a pathological phenotype, such as that of obesity, dyslipidemia, metabolic syndrome, hypertension, and cancers. The failure of the skeletal muscle mitochondria to oxidize fat properly leads to ectopic lipid deposits. Cellular infiltration by excess triglycerides can impair cellular function and can also lead to oxidative stress through increased ceramide formation, increased lipid peroxidation, inflammatory cytokine production, and excess Reactive Oxygen Species (ROS) formation [106, 107]. When ROS production is increased, the disturbed balance results in a prooxidative condition. This oxidative stress can then damage various cellular structures and triggers an inflammatory response associated with adiposity, insulin resistance, and metabolic syndrome, suggesting that oxidative stress could be an early event in the pathology of these chronic diseases. $[108,109]$. Recently, much evidence has emerged showing that environmental toxins, including Persistent Organic Pollutants (POPs), can affect mitochondrial function and subsequent insulin resistance. In this regard, many herbicides, insecticides, rodenticides, industrial products, and industrial toxic wastes might affect mitochondrial function and cause pro-oxidative conditions [110-112].

\section{Exposure Monitoring}

Various molecules, involved in antioxidant and detoxification pathways, have potential application as biomarkers in biomonitoring and risk assessment.

The National Academy of Science, in 1987, defined a biomarker as "a xenobiotically induced variation in cellular or biochemical components or processes, structures, or function that is measurable in a biological system (body fluids, cells, or tissues)" [113]. Biomarker responses in fish are routinely used to assess exposure of anthropogenic chemicals in the aquatic environment. The use of biomarkers could complement the current methods used to determine the presence of environmental pollutants and might also help to predict human health risks [114]. Among the various types of biomarkers in ecotoxicological studies are the following: cytochrome P450 activity (an indicator of the exposure and effect of organic contaminants, such as polycyclic aromatic hydrocarbons (PAHs), PCBs, and pesticides), the inhibition of Acetyl cholinesterase (AChE) activity (a biomarker of the exposure and effect of organophosphate (OP) and carbamate (CAR), metallothionein synthesis in hepatic and other tissues (exposure to the metals $\mathrm{Zn}, \mathrm{Cu}, \mathrm{Cd}, \mathrm{Hg}$, and $\mathrm{Fe}$ and some pesticides), antioxidant enzymes such as superoxide dismutase, catalase, and glutathione transferase (exposure to ROS, free radicals, and pollutants causing oxidative stress and lipid peroxidation, such as pesticides and metals), and vitellogenin induction (estrogenic substances) [115-121]. Recently, redox markers have been used to biologically define Multiple Chemical Sensitivity (MCS) [122]. The development and use of biomarkers in ecotoxicology for providing sensitive early warning signals of incipient ecological damage is motivated by the inherent instabilities of many EDCs and the chemical specificity of some biomarkers on underlying mechanisms of toxic action. However, little is known about how cocktail effects affect these biomarker responses, and chemical safetylevels are traditionally based on experiences from lab studies with single chemicals, which are unfortunate as a chemical can be more toxic when it is mixed with other chemicals, because of the cocktail effect, for example, if there is a risk for increased bioavailability of certain pollutants that can result in harmful bioaccumulation or if there is an increased risk for accumulation of toxic metabolites or if there is an increased risk for depletion of endogenous hormones. The possible involvement of receptor crosstalks, inhibition, or activation on key biotransformation enzyme and transporter proteins such and multidrug resistance-associated proteins needs to be addressed for estimation of possible adverse pharmacokinetic interactions [123].

\section{Concluding Remarks}

EDCs clearly contribute to diverse male and female human health problems such as decreased male sperm counts, increased incidence of hypospadias and cryptorchidism, altered male: female birth sex ratios, decreased fertility, and increased incidence of breast and testicular cancers and may be responsible for neurodevelopmental deficits in children. Recently, human exposure to EDCs has been associated with the development of some of the main diseases of the industrialized world, particularly metabolic disorders like obesity, diabetes, and metabolic syndrome. POPs such as organochlorine pesticides, dioxins, and polyfluoroalkyl compounds and no persistent pollutants such as BPA and several phthalates are endowed with metabolic disruption activity. The European Union has sponsored several international 
TABLE 2: Examples of ongoing European research projects on endocrine disrupters [103].

\begin{tabular}{lll}
\hline $\begin{array}{l}\text { Project acronym and } \\
\text { duration }\end{array}$ & Project title & Research team \\
\hline & & \\
& $\begin{array}{l}\text { Contaminants in food and } \\
\text { feed: inexpensive detection }\end{array}$ & Participating laboratories: \\
fONFFIDENCE & for control of exposure & BE, UK, IT, FI, CH) \\
$(2008-2012)$ &
\end{tabular}

Focus

The main aim is to further improve food safety in Europe by the development of faster and more cost-efficient methods for the detection of a wide range of chemical contaminants (persistent organic compounds, perfluorinated compounds, and heavy metals) in different food and feed commodities

Arctic health risks: Impacts on health in the Arctic and

ARCRISK (2009-2013) Europe owing to climate-induced changes in contaminant cycling

European coordination action on human biomonitoring

Life cycle assessment of environment-compatible flame retardants (prototypical case study)

Obesogenic endocrine disrupting chemicals:

OBELIX (2009-2013) linking prenatal exposure to the development of obesity later in life
Participating laboratories: 22 (NO, SE, DK, FI, DE, UK, ES, SI, CH, CZ, RU, CA)

Participating laboratories: 35 (BE, DE, ES, UK, FR, DK, IT, EE, SI, NL, AT, RO, LT, HR, EL, CY, PT, SE, $\mathrm{NO}, \mathrm{HU}, \mathrm{CH}, \mathrm{SK}, \mathrm{PL}, \mathrm{CZ}$, IE, FI, LU)

Participating laboratories: 12 (NL, UK, SE, DE, IT)

Participating laboratories: 7 (NL, BE, NO, FR, SK)
The main aim will be to study the influence of climate change on contaminant spreading and transfer and the resultant risk to human populations in the Arctic and other areas of Europe

The main goal is to develop a coherent approach to human biomonitoring in Europe, addressing the aims of Action 3 of the European Environment and Health Action Plan.

ENFIRO will offer a prototypical case study on substitution options for BFRs resulting in a comprehensive dataset on viability of production and application, environmental safety, and a complete life cycle assessment

Examination of the hypothesis that prenatal exposure to endocrine disrupting compounds in food plays a role in the development of obesity later in life research project to investigate various obesity-related effects from EDCs exposure (Table 2), regarding the diverse types of chemical compounds involved, the influence of climate changes on contaminant spreading, the age of exposition (developmental basis of adult diseases), food safety, and human bio monitoring. A greatest challenge in environmental toxicology is to understand effects of mixture toxicity (cocktail effects) in humans and in wildlife. Considering that metabolic perturbations are only one small aspect of the EDCs-related problems to be solved and that we know only the tip of the iceberg, new integrative approaches are required to understand the complexity of the cocktail effect and its consequences when exposure occurs at various life stages [124]. Procedures for risk assessment of chemical mixtures, combined, and cumulative exposures are under development, but the scientific database needs considerable expansion [114]. In particular, there is a lack of knowledge on how to monitor effects of complex exposures. As described here, solid evidence shows that endocrine disrupters can interact and even produce synergistic effects. They may act during sensitive time windows and biomonitoring their effects in epidemiological studies is a challenging task. The potential health effects of combined exposures make the risk assessment process more complex compared to the assessment of single chemicals. Techniques and methods need to be further developed to fill data gaps and increase the knowledge on harmful exposure combinations.

\section{References}

[1] http://ec.europa.eu/health/nutrition_physical_activity/docs/ implementation_report_en.pdf.

[2] Y. C. Klimentidis, T. M. Beasley, H. Y. Lin et al., "Canaries in the coal mine: a cross-species analysis of the plurality of obesity epidemics," Proceedings of the Royal Society B, vol. 278, no. 1712, pp. 1626-1632, 2011.

[3] L. M. Donini, M. Cuzzolaro, G. Spera et al., "Obesity and eating disorders. Indications for the different levels of care. An Italian expert consensus document," Eating and Weight Disorders, vol. 15, no. 1-2, pp. 1-31, 2010.

[4] L. M. Donini, A. Brunani, A. Sirtori et al., "Assessing disability in morbidly obese individuals: the Italian society of obesity test for obesity-related disabilities," Disability and Rehabilitation, vol. 33, no. 25-26, pp. 2509-2518, 2011.

[5] E. Kassi, P. Pervanidou, G. Kaltsas, and G. Chrousos, "Metabolic syndrome: definitions and controversies," BMC Medicine, vol. 9, article 48, 2011.

[6] C. Lubrano, M. Saponara, G. Barbaro et al., "Relationships between body fat distribution, epicardial fat and obstructive sleep apnea in obese patients with and without metabolic syndrome," PLoS ONE, no. 10, Article ID e47059, 72012.

[7] E. J. DeMaria, "Bariatric surgery for morbid obesity," The New England Journal of Medicine, vol. 356, no. 21, pp. 2176-2183, 2007.

[8] C. Lubrano, A. Cornoldi, M. Pili et al., "Reduction of risk factors for cardiovascular diseases in morbid-obese patients following 
biliary-intestinal bypass: 3 years' follow-up," International Journal of Obesity, vol. 28, no. 12, pp. 1600-1606, 2004.

[9] C. Lubrano, S. Mariani, M. Badiali et al., "Metabolic or bariatric surgery long-term effects of malabsorptive versus restrictive bariatric techniques on body composition and cardiometabolic risk factors," International Journal of Obesity, vol. 34, no. 9, pp. 1404-1414, 2010.

[10] I. Bondia-Pons, L. Ryan, and J. A. Martinez, "Oxidative stress and inflammation interactions in human obesity," Journal of Physiology and Biochemistry, vol. 68, no. 4, pp. 701-711, 2012.

[11] F. Rossi, C. Bertone, F. Montanile et al., "HDL cholesterol is a strong determinant of endothelial progenitor cells in hypercholesterolemic subjects," Microvascular Research, vol. 80, no. 2, pp. 274-279, 2010.

[12] K. A. Thayer, J. J. Heindel, J. R. Bucher, and M. A. Gallo, "Role of environmental chemicals in diabetes and obesity: a national toxicology program workshop review," Environmental Health Perspectives, vol. 120, no. 6, pp. 779-789, 2012.

[13] L. Salvatori, F. Caporuscio, L. De Girolamo et al., "Morphological and functional features of human omental and subcutaneous adipose-derived stem cells isolated from obese patients," Endocrine Reviews, Supplement 1, vol. 31, no. 3, p. S1351 P2-468, 2010.

[14] P. F. Baillie-Hamilton, "Chemical toxins: a hypothesis to explain the global obesity epidemic," Journal of Alternative and Complementary Medicine, vol. 8, no. 2, pp. 185-192, 2002.

[15] T. Colborn, F. S. vom Saal, and A. M. Soto, "Developmental effects of endocrine-disrupting chemicals in wildlife and humans," Environmental Health Perspectives, vol. 101, no. 5, pp. 378-384, 1993.

[16] H. Marini, L. Minutoli, F. Polito et al., "Effects of the phytoestrogen genistein on bone metabolism in osteopenic postmenopausal women: a randomized trial," Annals of Internal Medicine, vol. 146, no. 12, pp. 839-847, 2007.

[17] M. Atteritano, H. Marini, L. Minutoli et al., "Effects of the phytoestrogen genistein on some predictors of cardiovascular risk in osteopenic, postmenopausal women: a two-year randomized, double-blind, placebo-controlled study," Journal of Clinical Endocrinology and Metabolism, vol. 92, no. 8, pp. 30683075, 2007.

[18] H. Marini, A. Bitto, D. Altavilla et al., "Breast safety and efficacy of genistein aglycone for postmenopausal bone loss: a follow-up study," Journal of Clinical Endocrinology and Metabolism, vol. 93, no. 12, pp. 4787-4796, 2008.

[19] H. Marini, L. Minutoli, F. Polito et al., "OPG and sRANKL serum concentrations in osteopenic, postmenopausal women after 2-year genistein administration," Journal of Bone and Mineral Research, vol. 23, no. 5, pp. 715-720, 2008.

[20] H. Marini, A. Bitto, D. Altavilla et al., "Efficacy of genistein aglycone on some cardiovascular risk factors and homocysteine levels: a follow-up study," Nutrition, Metabolism and Cardiovascular Diseases, vol. 20, no. 5, pp. 332-340, 2010.

[21] M. Castelli, B. Rossi, F. Corsetti et al., "Cadmium and Pb in blood of Italian subjects: preliminary report of current trends," in 11. Italian-Hungarian Symposium on Spectrochemistry. New Challenges in Human Health Protection: Anthropic and Remote Areas. Venice (Italy). October 19-24, 2003. Abstract Book, S. Caroli and C. Ferreri, Eds., p. 142, Istituto Superiore di Sanità (ISTISAN Congressi 03/C3), Rome, Italy, 2003.

[22] P. B. Tchounwou, C. G. Yedjou, A. K. Patlolla, and D. J. Sutton, "Heavy metal toxicity and the environment," Molecular, Clinical and Environmental Toxicology Experientia Supplementum, vol. 101, pp. 133-164, 2012.

[23] M. Brama, L. Gnessi, S. Basciani et al., "Cadmium induces mitogenic signaling in breast cancer cell by an ER $\alpha$-dependent mechanism," Molecular and Cellular Endocrinology, vol. 264, no. 1-2, pp. 102-108, 2007.

[24] 2004, http://ec.europa.eu/food/food/chemicalsafety/contaminants/scoop_3-2-11_heavy_metals_report_en.pdf.

[25] M. Castelli, B. Rossi, F. Corsetti et al., "Levels of cadmium and lead in blood: an application of validated methods in a group of patients with endocrine/metabolic disorders from the Rome area," Microchemical Journal, vol. 79, no. 1-2, pp. 349-355, 2005.

[26] C. D. Wren, "Cause-effect linkages between chemicals and populations of mink (Mustela vision) and otter (Lutra canadensis) in the Great Lakes basin," Journal of Toxicology and Environmental Health, vol. 33, no. 4, pp. 549-585, 1991.

[27] P. D. Hansen, H. von Westernhagen, and H. Rosenthal, "Chlorinated hydrocarbons and hatching success in Baltic herring spring spawners," Marine Environmental Research, vol. 15, no. 1, pp. 59-76, 1985.

[28] J. F. Leatherland, "Endocrine and reproductive function in Great Lakes salmon," in Chemically Induced Alterations in Sexual and Functional Development: The Human-Wildlife Connection, T. Colborn and C. Clement, Eds., pp. 129-146, Princeton Scientific Publishing, Princeton, NJ, USA, 1992.

[29] A. C. Pesatori, D. Consonni, A. Tironi, C. Zocchetti, A. Fini, and P. A. Bertazzi, "Cancer in a young population in a dioxincontaminated area," International Journal of Epidemiology, vol. 22, no. 6, pp. 1010-1013, 1993.

[30] A. M. Calafat and L. L. Needham, "Human exposures and body burdens of endocrine-disrupting chemicals," in EndocrineDisrupting Chemicals: From Basic Research to Clinical Practice, A. C. Gore, Ed., pp. 253-268, Humana Press, Totowa, NJ, USA, 2007.

[31] C. Casals-Casas, J. N. Feige, and B. Desvergne, "Interference of pollutants with PPARs: endocrine disruption meets metabolism," International Journal of Obesity, vol. 32, supplement 6, pp. S53-S61, 2008.

[32] D. M. Sheehan, E. Willingham, D. Gaylor, J. M. Bergeron, and D. Crews, "No threshold dose for estradiol-induced sex reversal of turtle embryos: how little is too much?" Environmental Health Perspectives, vol. 107, no. 2, pp. 155-159, 1999.

[33] F. S. vom Saal, B. T. Akingbemi, S. M. Belcher et al., "Chapel Hill bisphenol A expert panel consensus statement: integration of mechanisms, effects in animals and potential to impact human health at current levels of exposure," Reproductive Toxicology, vol. 24, no. 2, pp. 131-138, 2007.

[34] D. J. P. Barker, "The developmental origins of adult disease," European Journal of Epidemiology, vol. 18, pp. 733-736, 2003.

[35] M. K. Skinner, M. Manikkam, and C. Guerrero-Bosagna, "Epigenetic transgenerational actions of environmental factors in disease etiology," Trends in Endocrinology and Metabolism, vol. 21, no. 4, pp. 214-222, 2010.

[36] M. A. Hanson and P. D. Gluckman, "Developmental origins of health and disease: new insights," Basic and Clinical Pharmacology and Toxicology, vol. 102, no. 2, pp. 90-93, 2008.

[37] D. K. Morgan and E. Whitelaw, "The role of epigenetics in mediating environmental effects on phenotype," Nestle Nutrition Workshop Series: Pediatric Program, vol. 63, pp. 109-119, 2009. 
[38] E. Petrangeli, C. Lubrano, L. Ravenna et al., "Gene methylation of oestrogen and epidermal growth factor receptors in neoplastic and perineoplastic breast tissues," The British Journal of Cancer, vol. 72, no. 4, pp. 973-975, 1995.

[39] E. Petrangeli, C. Lubrano, F. Ortolani et al., "Estrogen receptors: new perspectives in breast cancer management," Journal of Steroid Biochemistry and Molecular Biology, vol. 49, no. 4-6, pp. 327-331, 1994.

[40] E. Diamanti-Kandarakis, J. P. Bourguignon, L. C. Giudice et al., "Endocrine-disrupting chemicals: an endocrine society scientific statement," Endocrine Reviews, vol. 30, no. 4, pp. 293342, 2009.

[41] J. Q. Chen, T. R. Brown, and J. Russo, "Regulation of energy metabolism pathways by estrogens and estrogenic chemicals and potential implications in obesity associated with increased exposure to endocrine disruptors," Biochimica et Biophysica Acta, vol. 1793, no. 7, pp. 1128-1143, 2009.

[42] L. M. Brown, L. Gent, K. Davis, and D. J. Clegg, "Metabolic impact of sex hormones on obesity," Brain Research, vol. 1350, pp. 77-85, 2010.

[43] P. S. Cooke and A. Naaz, "Role of estrogens in adipocyte development and function," Experimental Biology and Medicine, vol. 229, no. 11, pp. 1127-1135, 2004.

[44] P. A. Heine, J. A. Taylor, G. A. Iwamoto, D. B. Lubahn, and P. S. Cooke, "Increased adipose tissue in male and female estrogen receptor- $\alpha$ knockout mice," Proceedings of the National Academy of Sciences of the United States of America, vol. 97, no. 23, pp. 12729-12734, 2000.

[45] R. R. Newbold, "Prenatal exposure to diethylstilbestrol (DES)," Fertility and Sterility, vol. 89, no. 2, pp. e55-e56, 2008.

[46] A. Schecter, N. Malik, D. Haffner et al., "Bisphenol A (BPA) in U.S. food," Environmental Science and Technology, vol. 44, no. 24, pp. 9425-9430, 2010.

[47] P. Alonso-Magdalena, A. B. Ropero, M. P. Carrera et al., "Pancreatic insulin content regulation by the Estrogen receptor ER $\alpha$," PLoS ONE, vol. 3, no. 4, Article ID e2069, 2008.

[48] J. Miyawaki, K. Sakayama, H. Kato, H. Yamamoto, and H. Masuno, "Perinatal and postnatal exposure to bisphenol A increase adipose tissue mass and serum cholesterol level in mice," Journal of Atherosclerosis and Thrombosis, vol. 14, no. 5, pp. 245-252, 2007.

[49] J. J. Heindel and F. S. vom Saal, "Role of nutrition and environmental endocrine disrupting chemicals during the perinatal period on the aetiology of obesity," Molecular and Cellular Endocrinology, vol. 304, no. 1-2, pp. 90-96, 2009.

[50] K. Sakurai, M. Kawazuma, T. Adachi et al., "Bisphenol A affects glucose transport in mouse 3T3-F442A adipocytes," The British Journal of Pharmacology, vol. 141, no. 2, pp. 209-214, 2004.

[51] F. S. vom Saal, S. C. Nagel, B. L. Coe, B. M. Angle, and J. A. Taylor, "The estrogenic endocrine disrupting chemical bisphenol A, (BPA) and obesity," Molecular and Cellular Endocrinology, vol. 354, no. 1-2, pp. 74-84, 2012.

[52] N. K. Wilson, J. C. Chuang, M. K. Morgan, R. A. Lordo, and L. S. Sheldon, "An observational study of the potential exposures of preschool children to pentachlorophenol, bisphenol-A, and nonylphenol at home and daycare," Environmental Research, vol. 103, no. 1, pp. 9-20, 2007.

[53] J. L. Carwile and K. B. Michels, "Urinary bisphenol A and obesity: NHANES 2003-2006," Environmental Research, vol. 111, no. 6 , pp. 825-830, 2011.
[54] I. A. Lang, T. S. Galloway, A. Scarlett et al., "Association of urinary bisphenol A concentration with medical disorders and laboratory abnormalities in adults," The Journal of the American Medical Association, vol. 300, no. 11, pp. 1303-1310, 2008.

[55] D. Melzer, N. J. Osborne, W. E. Henley et al., "Urinary bisphenol A concentration and risk of future coronary artery disease in apparently healthy men and women," Circulation, vol. 125, no. 12, pp. 1482-1490, 2012.

[56] R. T. Zoeller, R. Bansal, and C. Parris, "Bisphenol-A, an environmental contaminant that acts as a thyroid hormone receptor antagonist in vitro, increases serum thyroxine, and alters RC3/neurogranin expression in the developing rat brain," Endocrinology, vol. 146, no. 2, pp. 607-612, 2005.

[57] J. Legler, "New insights into the endocrine disrupting effects of brominated flame retardants," Chemosphere, vol. 73, no. 2, pp. 216-222, 2008.

[58] R. M. Sargis, D. N. Johnson, R. A. Choudhury, and M. J. Brady, "Environmental endocrine disruptors promote adipogenesis in the 3T3-L1 cell line through glucocorticoid receptor activation," Obesity, vol. 18, no. 7, pp. 1283-1288, 2010.

[59] K. Nakamura, R. Moore, M. Negishi, and T. Sueyoshi, "Nuclear pregnane $\mathrm{X}$ receptor cross-talk with FoxA2 to mediate druginduced regulation of lipid metabolism in fasting mouse liver," The Journal of Biological Chemistry, vol. 282, no. 13, pp. 97689776, 2007.

[60] J. Gao, J. He, Y. Zhai, T. Wada, and W. Xie, “The constitutive androstane receptor is an antiobesity nuclear receptor that improves insulin sensitivity," The Journal of Biological Chemistry, vol. 284, no. 38, pp. 25984-25992, 2009.

[61] A. Moreau, M. J. Vilarem, P. Maurel, and J. M. Pascussi, "Xenoreceptors CAR and PXR activation and consequences on lipid metabolism, glucose homeostasis, and inflammatory response," Molecular Pharmaceutics, vol. 5, no. 1, pp. 35-41, 2008.

[62] H. Ren, L. M. Aleksunes, C. Wood et al., "Characterization of peroxisome proliferator-activated receptor $\alpha$-independent effects of PPAR $\alpha$ activators in the rodent liver: di-(2-ethylhexyl) phthalate also activates the constitutive-activated receptor," Toxicological Sciences, vol. 113, no. 1, Article ID kfp251, pp. 4559, 2009.

[63] K. W. Bock and C. Köhle, "Ah receptor: dioxin-mediated toxic responses as hints to deregulated physiologic functions," Biochemical Pharmacology, vol. 72, no. 4, pp. 393-404, 2006.

[64] M. A. Cimafranca, P. R. Hanlon, and C. R. Jefcoate, “TCDD administration after the pro-adipogenic differentiation stimulus inhibits PPAR $\gamma$ through a MEK-dependent process but less effectively suppresses adipogenesis," Toxicology and Applied Pharmacology, vol. 196, no. 1, pp. 156-168, 2004.

[65] http://www.who.int/ipcs/publications/en/ch3.pdf.

[66] L. Silvestroni, F. Rossi, M. Magnanti, C. Lubrano, V. Santiemma, and S. Palleschi, "A novel aspect of lindane testicular toxicity: in vitro effects on peritubular myoid cells," Reproductive Toxicology, vol. 13, no. 6, pp. 431-441, 1999.

[67] K. Heng, R. Anand-Ivell, K. Teerds, and R. Ivell, "The endocrine disruptors dibutyl phthalate (DBP) and diethylstilbestrol (DES) influence Leydig cell regeneration following ethane dimethane sulphonate treatment of adult male rats," International Journal of Andrology, vol. 35, no. 3, pp. 353-363, 2012.

[68] L. Silvestroni, F. Rossi, M. Magnanti, C. Lubrano, V. Santiemma, and S. Palleschi, "A novel aspect of lindane testicular toxicity: in vitro effects on peritubular myoid cells," Reproductive Toxicology, vol. 13, no. 6, pp. 431-441, 1999. 
[69] S. Basciani, M. Brama, S. Mariani et al., "Imatinib mesylate inhibits Leydig cell tumor growth: evidence for in vitro and in vivo activity," Cancer Research, vol. 65, no. 5, pp. 1897-1903, 2005.

[70] S. Basciani, S. Mariani, G. Spera, and L. Gnessi, "Role of plateletderived growth factors in the testis," Endocrine Reviews, vol. 31, no. 6, pp. 916-939, 2010.

[71] S. Mariani, S. Basciani, M. Arizzi, G. Spera, and L. Gnessi, "PDGF and the testis," Trends in Endocrinology and Metabolism, vol. 13, no. 1, pp. 11-17, 2002.

[72] C. Lubrano, F. Sciarra, G. Spera et al., "Immunoreactive EGF in human benign prostatic hyperplasia: relationships with androgen and estrogen receptors," Journal of Steroid Biochemistry and Molecular Biology, vol. 41, no. 3-8, pp. 683-687, 1992.

[73] E. Petrangeli, F. Sciarra, F. Di Silverio et al., "Effects of two different medical treatments on dihydrotestosterone content and androgen receptors in human benign prostatic hyperplasia," Journal of Steroid Biochemistry, vol. 30, no. 1-6, pp. 395-399, 1988.

[74] C. Lubrano, V. Toscano, E. Petrangeli et al., "Relationship between epidermal growth factor and its receptor in human benign prostatic hyperplasia," Journal of Steroid Biochemistry and Molecular Biology, vol. 46, no. 4, pp. 463-468, 1993.

[75] J. H. Wu, X. R. Jiang, G. M. Liu, X. Y. Liu, G. L. He, and Z. Y. Sun, "Oral exposure to low-dose bisphenol A aggravates testosterone-induced benign hyperplasia prostate in rats," Toxicology and Industrial Health, vol. 27, no. 9, pp. 810-819, 2011.

[76] D. Margel and N. E. Fleshner, "Oral contraceptive use is associated with prostate cancer: an ecological study," The British Medical Journal, vol. 1, no. 2, Article ID e000311, 2011.

[77] L. Ravenna, L. Salvatori, S. Morrone et al., "Effects of triptorelin, a gonadotropin-releasing hormone agonist, on the human prostatic cell lines PC3 and LNCaP," Journal of Andrology, vol. 21, no. 4, pp. 549-557, 2000.

[78] L. Ravenna, C. Lubrano, F. Di Silverio et al., "Androgenic and antiandrogenic control on epidermal growth factor, epidermal growth factor receptor, and androgen receptor expression in human prostate cancer cell line LNCaP," Prostate, vol. 26, no. 6, pp. 290-298, 1995.

[79] K. Kim, H. Lee, and K. Choi, "Bisphenol A and phthalate stimulated the growth of human prostate cancer cells and altered downstream target genes of ras signaling pathway," Endocrine Abstracts, vol. 29, article P751, 2012.

[80] P. Trimboli, S. Ulisse, F. M. Graziano et al., "Trend in thyroid carcinoma size, age at diagnosis, and histology in a retrospective study of 500 cases diagnosed over 20 years," Thyroid, vol. 16, no. 11, pp. 1151-1155, 2006.

[81] S. H. Golden, A. Brown, J. A. Cauley et al., "Health disparities in endocrine disorders: biological, clinical, and nonclinical factors-an endocrine society statement," Journal of Clinical Endocrinology and Metabolism, vol. 97, no. 9, pp. E1579-E1639, 2012.

[82] M. L. Lee, G. G. Chen, A. C. Vlantis, G. M. K. Tse, B. C. H. Leung, and C. A. Van Hasselt, "Induction of thyroid papillary carcinoma cell proliferation by estrogen is associated with an altered expression of Bcl-xL," Cancer Journal, vol. 11, no. 2, pp. 113-121, 2005.

[83] F. Grün and B. Blumberg, "Environmental obesogens: organotins and endocrine disruption via nuclear receptor signaling," Endocrinology, vol. 147, no. 6, pp. S50-S55, 2006.
[84] L. Turrio Baldassarri, C. La Rocca, N. Iacovella et al., "Determination of polycyclic aromatic hydrocarbons and polychlorobiphenyls in whole human blood by SFE-GC-MS," Organohalogen Compounds, vol. 40, pp. 285-288, 1999.

[85] C. Lubrano, “Obesità e inquinamento," Sicurezza Sanitaria, vol. 98, pp. 38-45, 2008.

[86] C. Lubrano, "Interferenti endocrini e obesità," in Geni e comportamenti. Scienza e arte della vita, F. Bottaccioli, Ed., pp. 219-226, Red Edizioni, Milan, Italy, 2009.

[87] EC, "Towards the establishment of a priority list of substances for further evaluation of their role in endocrine disruptionpreparation of a candidate list of substances as a basis for priority setting," Final Report by BKH Consulting Engineers, Delft, The Netherlands TNO Nutrition and Food Research, Zeist, The Netherlands, for the European Commission, EC DG ENV M0355008/1786Q/10/11/00, 2000.

[88] L. Turrio-Baldassarri, C. La Rocca, N. Iacovella et al., "Determination of polycyclic aromatic hydrocarbons and polychlorobiphenyls in whole human blood by SFE EGC-MS," Organohalogen Compounds, vol. 40, pp. 285-288, 1999.

[89] E. E. Hatch, J. W. Nelson, R. W. Stahlhut, and T. F. Webster, "Association of endocrine disruptors and obesity: perspectives from epidemiological studies," International Journal of Andrology, vol. 33, no. 2, pp. 324-332, 2010.

[90] http://www.who.int/ipcs/publications/en/ch3.pdf.

[91] W. Karmaus, J. R. Osuch, I. Eneli et al., "Maternal levels of dichlorodiphenyl-dichloroethylene (DDE) may increase weight and body mass index in adult female offspring," Occupational and Environmental Medicine, vol. 66, no. 3, pp. 143-149, 2009.

[92] A. Smink, N. Ribas-Fito, R. Garcia et al., "Exposure to hexachlorobenzene during pregnancy increases the risk of overweight in children aged 6 years," Acta Paediatrica, International Journal of Paediatrics, vol. 97, no. 10, pp. 1465-1469, 2008.

[93] C. Casals-Casas and B. Desvergne, "Endocrine disruptors: from endocrine to metabolic disruption," Annual Review of Physiology, vol. 73, pp. 135-162, 2011.

[94] M. A. Elobeid, M. A. Padilla, D. W. Brock, D. M. Ruden, and D. B. Allison, "Endocrine disruptors and obesity: an examination of selected persistent organic pollutants in the NHANES 19992002 data," International Journal of Environmental Research and Public Health, vol. 7, no. 7, pp. 2988-3005, 2010.

[95] S. Fierens, H. Mairesse, J. F. Heilier et al., "Dioxin/polychlorinated biphenyl body burden, diabetes and endometriosis: findings in a population-based study in Belgium," Biomarkers, vol. 8, no. 6, pp. 529-534, 2003.

[96] S. Sato, H. Shirakawa, S. Tomita et al., "Low-dose dioxins alter gene expression related to cholesterol biosynthesis, lipogenesis, and glucose metabolism through the aryl hydrocarbon receptor-mediated pathway in mouse liver," Toxicology and Applied Pharmacology, vol. 229, no. 1, pp. 10-19, 2008.

[97] J. Matthews and J. A. Gustafsson, "Estrogen receptor and aryl hydrocarbon receptor signaling pathways," Nuclear Receptor Signaling, vol. 4, article e016, 2006.

[98] J. Auwerx, "PPAR $\gamma$, the ultimate thrifty gene," Diabetologia, vol. 42, no. 9, pp. 1033-1049, 1999.

[99] J. N. Feige, L. Gelman, D. Rossi et al., "Activation of PPAR $\alpha$ and PPAR $\gamma$ by environmental phthalate monoesters," Toxicological Sciences, vol. 74, pp. 297-308, 2007.

[100] V. Zoete, A. Grosdidier, and O. Michielin, "Peroxisome proliferator-activated receptor structures: ligand specificity, molecular switch and interactions with regulators," Biochimica et Biophysica Acta, vol. 1771, no. 8, pp. 915-925, 2007. 
[101] T. Kanayama, N. Kobayashi, S. Mamiya, T. Nakanishi, and J. I. Nishikawa, "Organotin compounds promote adipocyte differentiation as agonists of the peroxisome proliferatoractivated receptor $\gamma /$ retinoid X receptor pathway," Molecular Pharmacology, vol. 67, no. 3, pp. 766-774, 2005.

[102] F. Grun, H. Watanabe, Z. Zamanian et al., "Endocrine-disrupting organotin compounds are potent inducers of adipogenesis in vertebrates," Molecular Endocrinology, vol. 20, no. 9, pp. 2141$2155,2005$.

[103] http://ec.europa.eu/research/endocrine/projects_ongoing_en. html.

[104] A. V. W. Nunn, J. D. Bell, and G. W. Guy, "Lifestyle-induced metabolic inflexibility and accelerated ageing syndrome: insulin resistance, friend or foe?" Nutrition and Metabolism, vol. 6, article 16, 2009.

[105] G. S. Hotamisligil, "Inflammation and metabolic disorders," Nature, vol. 444, no. 7121, pp. 860-867, 2006.

[106] B. B. Lowell and G. I. Shulman, "Mitochondrial dysfunction and type 2 diabetes," Science, vol. 307, no. 5708, pp. 384-387, 2005.

[107] M. M. Rogge, "The role of impaired mitochondrial lipid oxidation in obesity," Biological Research For Nursing, vol. 10, no. 4, pp. 356-373, 2009.

[108] J. B. Meigs, M. G. Larson, C. S. Fox, J. F. Keaney, R. S. Vasan, and E. J. Benjamin, "Association of oxidative stress, insulin resistance, and diabetes risk phenotypes: the framingham offspring study," Diabetes Care, vol. 30, no. 10, pp. 2529-2535, 2007.

[109] M. Krzystek-Korpacka, E. Patryn, D. Boehm, I. Berdowska, B. Zielinski, and A. Noczynska, "Advanced oxidation protein products (AOPPs) in juvenile overweight and obesity prior to and following weight reduction," Clinical Biochemistry, vol. 41, no. 12, pp. 943-949, 2008.

[110] S. Lim, Y. M. Cho, K. S. Park, and H. K. Lee, "Persistent organic pollutants, mitochondrial dysfunction, and metabolic syndrome," Annals of the New York Academy of Sciences, vol. 1201, pp. 166-176, 2010.

[111] M. Wu, H. Xu, Y. Shen, W. Qiu, and M. Yang, "Oxidative stress in zebrafish embryos induced by short-term exposure to bisphenol A, nonylphenol, and their mixture," Environmental Toxicology and Chemistry, vol. 30, no. 10, pp. 2335-2341, 2011.

[112] Yang Yj, Y. C. Hong, S. Y. Oh et al., "Bisphenol A exposure is associated with oxidative stress and inflammation in postmenopausal women," Environmental Research, vol. 109, no. 6, pp. 797-801, 2009.

[113] R. J. Huggett, J. J. Stegeman, D. S. Page, K. R. Parker, B. Woodin, and J. S. Brown, "Biomarkers in fish from Prince William Sound and the Gulf of Alaska: 1999-2000," Environmental Science and Technology, vol. 37, no. 18, pp. 4043-4051, 2003.

[114] I. Silins and J. Högberg, "Combined toxic exposures and human health: biomarkers of exposure and effect," International Journal of Environmental Research and Public Health, vol. 8, no. 3, pp. 629-647, 2011.

[115] A. Valavanidis, T. Vlahogianni, M. Dassenakis, and M. Scoullos, "Molecular biomarkers of oxidative stress in aquatic organisms in relation to toxic environmental pollutants," Ecotoxicology and Environmental Safety, vol. 64, no. 2, pp. 178-189, 2006.

[116] F. M. Farahat, C. A. Ellison, M. R. Bonner et al., "Biomarkers of chlorpyrifos exposure and effect in Egyptian cotton field workers," Environmental Health Perspectives, vol. 119, no. 6, pp. 801-806, 2011.

[117] J. W. Albers, D. H. Garabrant, S. Berent, and R. J. Richardson, "Paraoxonase status and plasma butyrylcholinesterase activity in chlorpyrifos manufacturing workers," Journal of Exposure Science and Environmental Epidemiology, vol. 20, no. 1, pp. 7989, 2010.

[118] M. Panemangalore, H. A. Dowla, and M. E. Byers, "Occupational exposure to agricultural chemicals: effect on the activities of some enzymes in the blood of farm workers," International Archives of Occupational and Environmental Health, vol. 72, no. 2, pp. 84-88, 1999.

[119] D. R. Livingstone, "Contaminant-stimulated reactive oxygen species production and oxidative damage in aquatic organisms," Marine Pollution Bulletin, vol. 42, no. 8, pp. 656-666, 2001.

[120] M. García-Closas, N. Malats, D. Silverman et al., "NAT2 slow acetylation, GSTM1 null genotype, and risk of bladder cancer: results from the Spanish bladder cancer study and metaanalyses," The Lancet, vol. 366, no. 9486, pp. 649-659, 2005.

[121] S. Abhishek, N. Kaur, S. Kaur, M. Lata, J. K. Sharma, and A. Sharma, "Association of GSTM1 and GSTT1 gene deletions with susceptibility to DNA damage in the pesticide-exposed workers of Punjab," Rejuvenation Research, vol. 13, no. 2-3, pp. 281-284, 2010.

[122] C. de Luca, M. G. Scordo, E. Cesareo et al., "Biological definition of multiple chemical sensitivity from redox state and cytokine profiling and not from polymorphisms of xenobioticmetabolizing enzymes," Toxicology and Applied Pharmacology, vol. 248, no. 3, pp. 285-292, 2010.

[123] M. C. Celander, "Cocktail effects on biomarker responses in fish," Aquatic Toxicology, vol. 105, no. 3-4, supplement, pp. 7277, 2011.

[124] A. Eveillard, F. Lasserre, M. de Tayrac et al., "Identification of potential mechanisms of toxicity after di-(2-ethylhexyl)phthalate (DEHP) adult exposure in the liver using a systems biology approach," Toxicology and Applied Pharmacology, vol. 236, no. 3, pp. 282-292, 2009. 


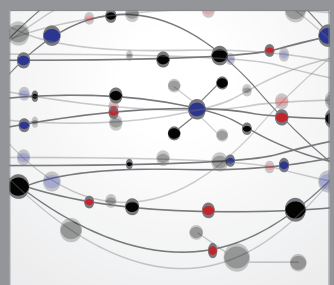

The Scientific World Journal
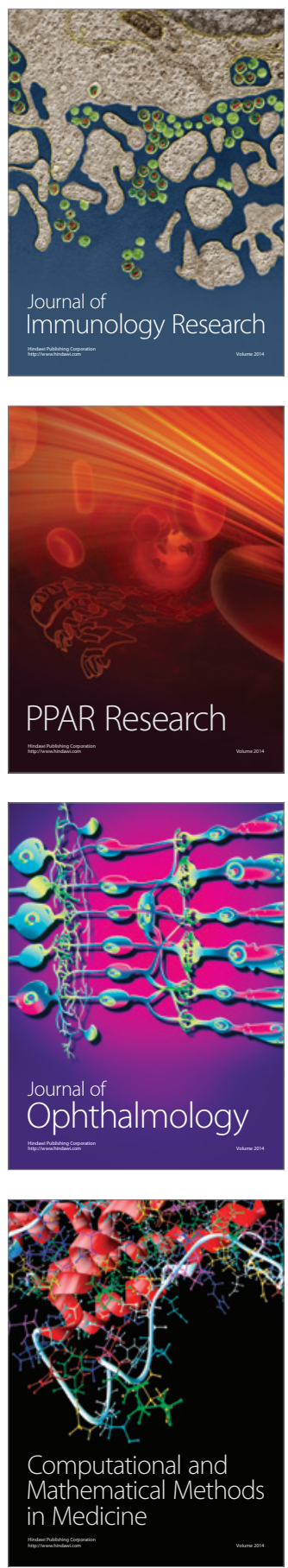

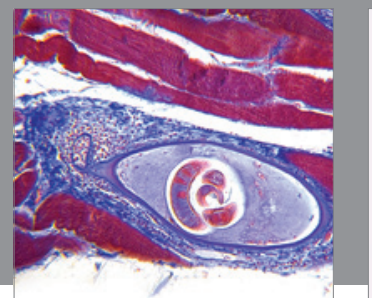

Gastroenterology

Research and Practice
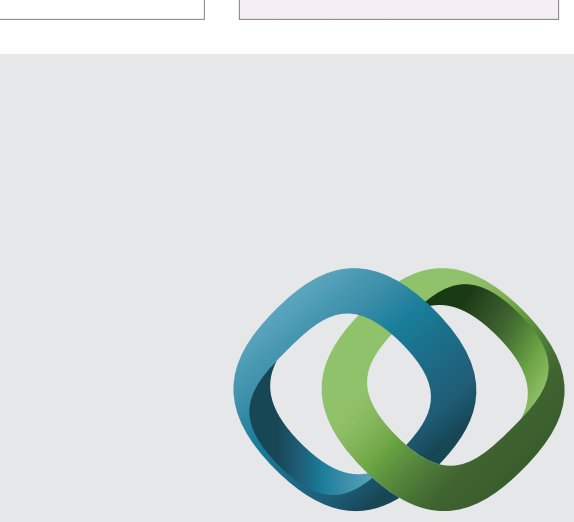

\section{Hindawi}

Submit your manuscripts at

http://www.hindawi.com
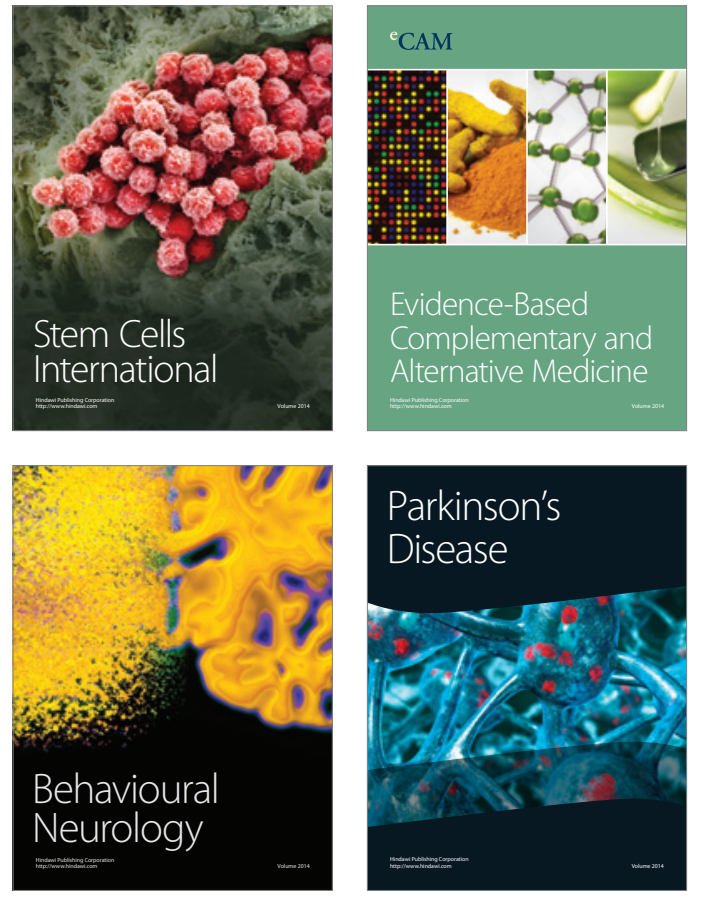
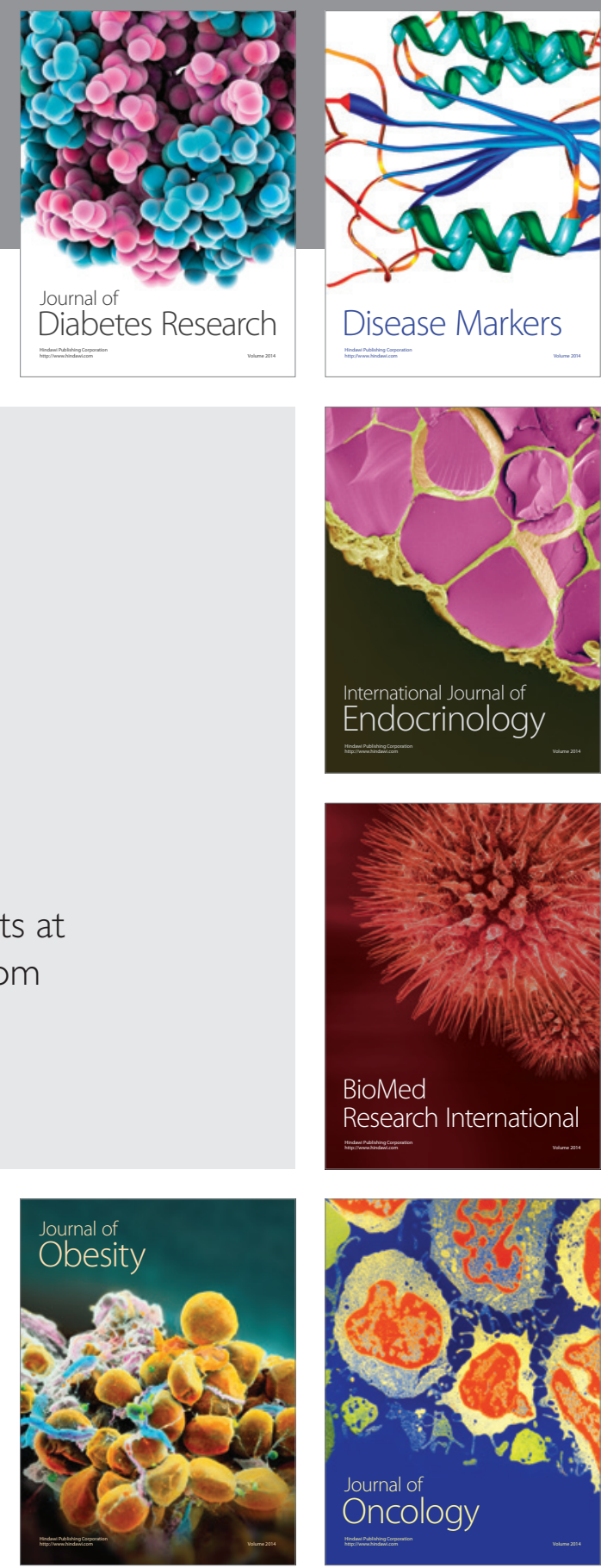

Disease Markers
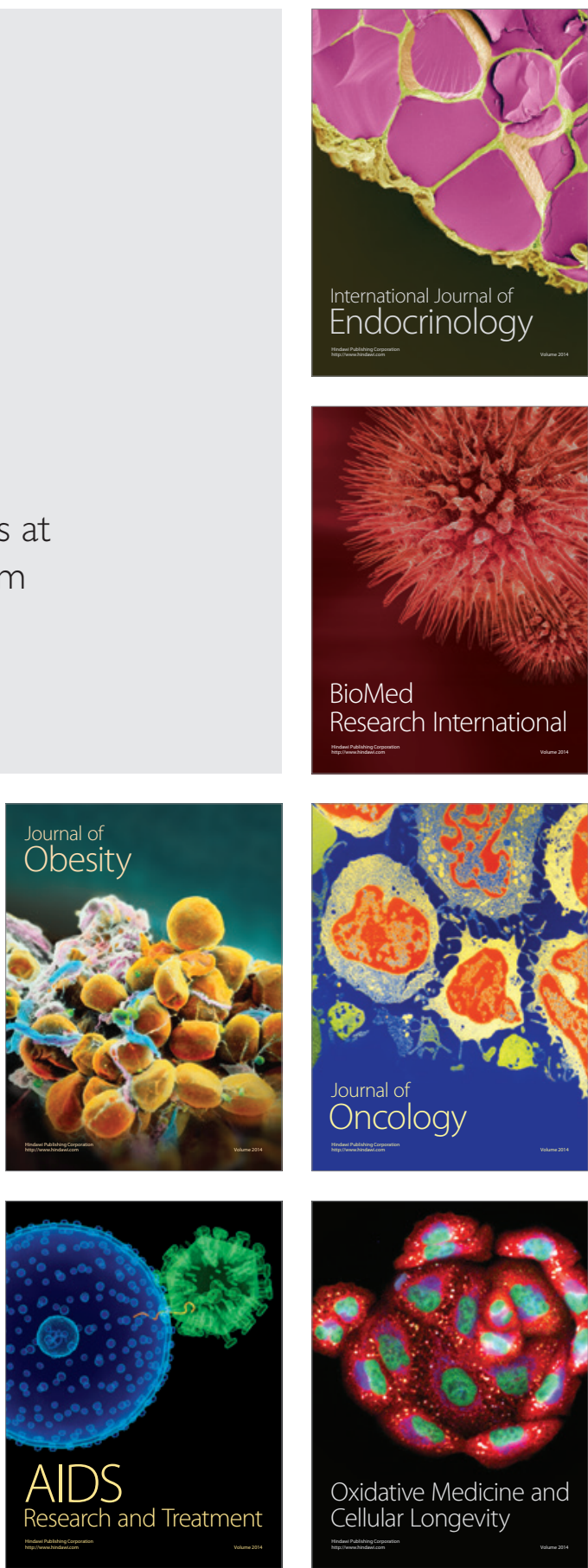